Postgrad. Med. J., (1966), 42, 294

\title{
ROTATING INTERNSHIP
}

\author{
Maurice CoOPe, M.B., (Birm.)* \\ Dudley Road Hospital Group, Birmingham
}

IN 1964 the Birmingham Regional Hospital Board advertised a number of supernumerary rotating internships in hospitals throughout the region. These posts were designed for medical graduates who had completed their preregistration appointments, and who were intending eventually to go into general practice. They were to be for one year in the grade of Senior House Officer (non-resident) and were financed by the Board. It was expected that the holder would spend his time in a variety of specialities, and some of the following were suggested: anaesthetics, ophthalmology, otorhinolaryngology (E.N.T.), dermatology, paediatrics, psychiatry, clinical pathology and public health. The choice was left to the successful applicant and the hospital group in which he worked.

I was appointed to one of these posts in September 1964. For reasons to be explained, I chose to do two 'months' anaesthetios, followed by three months' combined E.N.T., dermatology and ophthalmology, three months' paediatrics and finally three months' psychiatry. Before considering each of these in turn, it is necessary to make a few remarks about the local situation.

An appointment to the Dudley Road Hospital Group provided certain geographical advantages: besides a large general hospital with a busy neonatal unit, there was a mental hospital within half a mile and three special hospitals devoted to Ear, Nose and Throat, Eye and Skin diseases all within walking distance of one another in the oity two miles away. A second mental hospital was also available, though further out of the city, and I made personal arrangements to go to the Birmingham Children's Hospital.

\section{Anaesthetics}

A minimum of six months is required to become proficient at routine anaesthesia and this would probably be considered too large a slice out of a year's rotating appointment. However, I had already done four months'

*Correspondence to: Postgraduate Centre, Dudley Road Hospital, Birmingham 18 locum work and a funther two months' experience proved valuable. At Dudley Road Hospital a trainee anaesthetist spends the first month as assistant to a consultant, following which he joins the rota for emergency work, with progressively less supervision. Experience covers general surgery, maternity, E.N.T. and eye surgery, but little dentistry, which is perhaps a disadvantage for someone proposing to go into general practice. 'By the end of six months it should be possible to anaesthetise for almost any emergency, but while practical experience was excellent, there was not much theoretical teaching.

Anaesthetics should not perhaps be dismissed entirely from consideration in this itype of rotating internship. Quite apart from providing variety in general practice and an extra source of income, it is an excellent means of access to the local hospital, and in some areas, and especially abroad, a knowledge of anaesthetics may prove invaluable.

\section{E.N.T., Ophthalmology and Dermatology}

Indifferent teaching, lack of allotted time, and disinterest on the part of the student with examinations to pass in what are considered more important subjeots, often combline to allow qualification with very poor knowledge of what, to the general practitioner, are most impontant branches of medicine. My own knowledge was embarrasingly scanty, and initially I could claim a positive disinterest in some of these subjects. This was soon dispelled, and by the end of the year I found them as full of interest as any other branch of medicine.

The three hospitals are olose together in the centre of the city, and introductions having been made, I was given complete freedom to allocate my own time-table to the best advantage. My schedule worked out as follows: 9-11 a.m.-Birmingham and Midland Eye Hospital: 11.15 a.m.-1.00 p.m.-Birmingham and Midland Ear and Throat Hospital; 2-4 p.m. -The Skin Hospital. The Eye Hospital is most active in the mornings. when on average between three and four hundred patients, both new and old, have to be seen in a session. The casuality department is very busy; this is of 
great importance, as it is here that one learns most. However, at first I spent some frustrating days being passed from one person to another, since no one knew what I was meant to be doing. Then fotunately there was a crisis in the junior hosplital staffing arrangements and I was taken on as a locum for two weeks. Although this prevented my altendance at the other hospitalls, it paid ample dividends; not only was it an interesting and valuable experience, but I soon became "one of the boys" and was subsequently allowed a large measure of autonomy in the hospital routine. I could now see as many new and old patients as I was able and nobody objected to my doing some nights on for casualty. I also attended special clinios for glaucoma and detachment, but would recommend these for occasional visits only.

New casualty patients arrived at the Ear and Throat Hospital between ten and twelve o'clock, and I had made arrangements for these to be seen by me. I spent most of the first week or so learning to manipulate the instruments essen'tial in this specialty. After this I gradually did more on my own, referring doubutul or difficult problems to the registrar. I bothered little about theatre work, partly because I had seen a good deal while anaesthetising, but also because hours spent in the casuality department were more rewarding. I also arranged for patients to come back at times when I could follow them up.

At the Skin Hospital in the afternoons, I was mainly an observer, but was not allowed to remain a very passive one for long. After the first fortnight I was asked to describe each condition, make a diagnosis and suggest treatment or further investigations. This does of course considerably prolong the clinic and I was fortunate in having consultants who were willing to spend time teaching in this way. There were also twice-monthly meetings, one in basic dermatology and the other to show conditions of interest from the preceding month, and these I attended.

When it comes to treatment. dermat logists tend to be individualists and this can he very muddling for a beginner. During the whole of the year, but in dermatology particularly, I found it advisable to keep notes on a card index system. These are now of considerable use.

Various points anise from these three months. In general, I found that I learnit at a vastly greater rate than as a student, possibly because of greater interest, but mainly because of greater participation and acceptance of responsibility for patients. Even so, the time allotted was not quite long enough and I would have preferred an extra month. Working at three specialties together was sometimes confusing, but they fitted in so well that none of the day was wasted. It is essential to know what to do at the start and in retrospect I wasted about a quanter of my time finding out how to set about the task. Finally, although a locum appointment was essential in ophthalmology, I did not find it necessary in the other two specialities.

By the end of three months, I had learnt the basic essentials in each specialty and no more. I could handle a small variety of instruments with some technical assurance; I had looked at a large number of normal ears, throats and noses; and I felt that I could diagnose most of the common eye, E.N.T. and skin diseases, and at least had acquired a basis on which to build in later years.

\section{Paediatrics}

Sick children provide some of the most worrying problems in general practice, and I felt that paediatrics should be included in the rotating internship. Here, more than ever, it is essential to have some responsibility, and I found that ward rounds or examining ohildren in hospital were of much less value than working in a casuality or out-patient department. I, therefore spent mudh of the time in the Casualty Department of the Birmingham Ohildren's Hospital, where about sixty children a day are seen, with problems ranging from small cuts to major trauma and from colds to a wide variety of serious illnesses. This experience cannot be bettered, especially if it possible to work as a locum. I also spent some weeks at Dudley Road Hospital doing locums and found that the large number of neonatal beds and a small premature baby unit provided a different and valuable kind of experience.

In retrospect, I feel that a full-time job in paediatrics would be preferable, and that three months is too short. Of all specialties I found it the most difficult in which to take advantage of the existing organisation; it is not easy to take a continued interest in patients who are not your own and there is a tendency to drift along as an observer. In fact, the hardest thing in the year's appoinitment was to maintain an interest when the impetus of responsibility was removed.

i:

\section{Psychiatry}

During the last three months I spent part of the time seeing psychiatric referrals from 
the general wards at Dudley Road Hospital, and the rest working at All Saints and Higheroft Mental Hospitals. The latter time was divided between out-patients (three clinics a week) and interviewing new patients on the wards. Again I have seen a wide variety of conditions and have gradually become conversant with the Mental Health Act. In the last few weeks I attended some out-patient sessions at the Children's Hospital. The most important part of this period has been the opportunity to learn the technique of taking psychiatric case histories.

\section{Discussion and Conclusions}

Medicine is such a vast subject that one can only hope to gain a general grounding at medical school, later specialising in a particular field, which takes many hard years of learning and further examinations. Paradoxically, it is possible to enter general practice, probably the hardest of specialities to practise well, without any further education. I am not suggesting that one cannot learn in general practice and certainly there are many aspects that cannot be learnt in hospital, but it seems a great pity that such a vast array of concentrated clinical material, together with specialist experience and guidance, should be ignored. There is however a limit to the time which the intending general practitioner wishes to spend in hospital and for this reason some form of rotating appointment seems to be the ideal solution.

Good preliminary organisation is vital because of the constant switching of jobs. Introductions and discussion with the previous occupant will prevent time being wasted. Active participation and having to worry about patients is also essential, but it is important not to be regarded as an ordinary houseman, so that maximum flexibility can be maintained. This may make it difficult to fit a rotating intern $\stackrel{2}{c}$

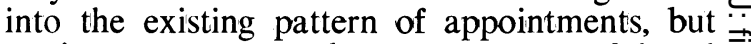
as time goes on one becomes more useful and can share some of the work load. In general, outpatients and casualty are the place to work, and a busy department is a gold mine of clinical material and experience.

The specialties I chose were those I knew least about and which I thought would be of most value in general practice. Obstetrics and gynaecology was intentionally excluded as requiring a minimum of six months. Other subjects could be considered depending on local circumstances, for example geriatrics, casualty and orthopaedics, clinical pathology, electrocardiography and public health. The latter would be valuable for someone intending to practise in the area of his rotating internship, because it would introduce him to the local social services.

It may be that eighteen months would be more suitable than a year, in which case a full six months could be devoted to paediatrics, and this could be followed by six months of obstet rics and gynaecology, thus completing a two year course. If such a scheme were to be accepted as part of the training for genera practice, it might then be possible to modify the teaching of some of these subjects in the undergraduate curriculum.

I would like to thank the Birmingham Regional Hospital Board for appointing me, the many Consultants and Registrars who spent a great deal of extra time teaching me, and the junior medical staff for their co-operation in what has been a most interesting and enjoyable year. 